\title{
Nitrogen Doped Carbon Nanofibers Derived from Water-Soluble Precursors
}

\author{
Lee D. Cremar ${ }^{1 *}$, Ben Jones ${ }^{1}$, Nicole Martinez ${ }^{1}$, Gustavo Mejia ${ }^{1}$, Hilario Cortez ${ }^{1}$, Edgar Muñoz ${ }^{1}$, Rocío \\ $\mathrm{Nava}^{2}$, and Karen Lozano ${ }^{1^{*}}$ \\ ${ }^{1}$ Mechanical Engineering Department, University of Texas-Rio Grande Valley, 1201 West University Drive, \\ Edinburg, TX 78539, USA \\ ${ }^{2}$ Instituto de Energías Renovables, Universidad Nacional Autónoma de México. Privada Xochicalco s/n, 62580 \\ Temixco, Morelos, México \\ Email: karen.lozano@utrgv.edu
}

\begin{abstract}
Nitrogen doped carbon fibers were synthesized from polyvinyl alcohol (PVA), a water soluble precursor. The PVA fine fibers were first developed by centrifugally spinning an aqueous based solution using Forcespinning® technology. The precursor fibers were then exposed to sulfuric acid vapors to partially carbonize and stabilize the fibers for further heat treatment. For nitrogen doping, the fibers were exposed to two different heat treatment routes. One was under a nitrogen atmosphere at $850^{\circ} \mathrm{C}$ followed by exposure to ammonia gas at $500^{\circ} \mathrm{C}$. The second route consisted of heating the treated fibers in pure ammonia gas only, up to $850^{\circ} \mathrm{C}$. Both heating schemes resulted in carbon based fibers that showed evidence of nitrogen content as shown by energy-dispersive X-ray spectroscopy. The second route showed an effective doping of the carbon fiber with nitrogen atoms, measured by X-ray photoelectron spectroscopy, which indicated that the nitrogen atoms were fully incorporated into the carbon framework.
\end{abstract}

Keywords: polyvinyl alcohol, carbon nanofiber, Forcespinning®.

\section{Introduction}

Carbon-based materials have many applications in a wide range of areas such as electrode components (energy conversion and storage applications), filtration, structural-reinforcement, oil absorption, and electromagnetic shielding to mention some [1]. Carbon fibers, in particular have been extensively used in the aerospace, sports, and automobile industries. It is estimated that the global carbon fiber market has grown to over 12,500 tons per year, indicating that carbon fiber has become not only of great technological importance but a strong commercial entity. Carbon fibers also have the potential to undergo chemical modification or doping to obtain novel material properties. These fibers may find potential applications in smart textiles such as in thermoelectric fabrics, where materials could produce electricity by harvesting heat generated by the body [2]. Such a technology would provide a new way for developing novel power generating clothing and self-powered portable electronics. Durable and flexible thermoelectric felts, incorporating doped carbon-based materials, are a promising alternative to traditional thermoelectric alloy based materials [3-5]. Most commercially available thermoelectric materials consist of inorganic bismuth telluride based alloys which operate at portable device temperatures (e.g. below $200^{\circ} \mathrm{C}$ ) and possess an efficiency or figure of merit ZT close to one [6, 7]. A high figure of merit (ZT) is desirable and can be produced by increasing the Seebeck coefficient $(\alpha)$ and electrical conductivity while keeping a low thermal conductivity (k). Recent studies have shown and predicted improvement in the thermoelectric output by the doping of carbon nanotubes (CNTs) [8]. The improved Seebeck effect by impurity doping of CNTs has shown the possibility to make organic thermoelectric devices $[9,10]$ in addition to nanotransitors, sensors, and diodes.

A few studies have shown the effects of doping carbon fibers, for example, Choi et al. studied the doping of fibers to develop supercapacitor electrodes [1] in which the pyrolysis of a nitrogen containing polymer was electrochemically grown on carbon fiber paper. Other studies have developed doped carbon 
fibers through electrocatalysts in metal-air batteries [11] where polystyrene and polyacrylonitrile underwent pyrolysis to form doped carbon fiber. Previous work has shown the doping of CNTs by either arc growth methods whereby nitrogen is introduced during pyrolysis or by chemical modification after synthesis [3, 9]. Results of these studies have indicated that nitrogen doping of CNTs results in a negative Seebeck due to strong donor states [12]. The n-type or electron carrier behavior is an important component of thermoelectric modules where hetero-junctions improve the overall efficiency. In this study we demonstrate the production of an " $n$ "-type material by nitrogen doping of the carbon fiber produced by pyrolytic routes, which results in the introduction of nitrogen to the carbon backbone.

A traditional and common method for producing carbon fibers is based on oxidation, carbonization, and graphitization of polyacrylonitrile (PAN) fibers. PAN has been the precursor of choice due to its high-tensile strength, though the high cost associated with the low yield, energy intensive oxidation stabilization steps, and high carbonization temperature, has hindered its wide acceptance as the material of choice for many applications. The usage of PAN based carbon fibers has therefore been limited to high performance applications. During the carbon conversion process, about $50 \%$ of PAN mass is lost and its volatiles require abatement methods to control the toxic species. The costs associated with postprocessing techniques such as stabilization, sizing, surface treatment, and material handling are low compared to the cost of the raw material (PAN). Recent attempts have been made to use alternative lower cost precursors such as meso-phase pitch based carbon fiber [13]. Alternate precursors such as PVA are ideal for carbon fiber production due to its low toxicity, cost effectiveness, and sufficient carbon content (54\% carbon by mass) [14, 15], and provide the sufficient mechanical strength for applications in filtration and electrodes.

In the case of carbon fibers, there are several methods available to produce fine fibers (nano to single digit micron) such as: wet chemistry methods [16], solution and melt blowing, and spinning methods (wet, dry and melt spinning). Wet chemistry methods still have low nanofiber (NF) yield and significant scalability issues. Solution and melt blown $[17,18]$ processes have been proven reliable and cost effective for micron size fibers, although for NFs, the process consumes large amount of heated gas and is not feasible for industrial scale up. Fibers produced through electrospinning [19-21] can range from tens of nanometers to a few micrometers, however at the lab scale, the outcome is low, averaging 0.01-1.0 gram per hour. Other methods, such as "Island-in-the-Sea" bi-component fiber spinning, combined with thermo-chemical stabilization and carbonization, have shown to produce continuous and unidirectional carbon NFs with various shapes [22]. However, the "fugitive" polymer may require removal by an organic solvent at a specified temperature, and therefore costly if extended to mass scale production.

The Forcespinning® (FS) method has shown capability to produce fine fibers from melt and solution spinning through centrifugal spinning. Since it does not require electric fields, it broadens the choice of materials to be spun into NFs $[21,23,24]$. The process at the industrial scale has shown production rates of up to hundreds of meters per minute depending on desired basis weight, which is highly controllable in the process. Herein, nitrogen doped carbon fibers were mass produced by converting the PVA fine fibers to carbon NFs through a dehydration process, induced by exposure to acid vapor up to $200^{\circ} \mathrm{C}$ described by Cremar et al. [25-27], followed by carbonization at low temperatures $\left(T<800^{\circ} \mathrm{C}\right)$ in an inert gas or in pure ammonia gas.

\section{$2 \quad$ Materials and Methods}

\section{$2.1 \quad$ Materials}

Polyvinyl alcohol (Average $\mathrm{M}_{\mathrm{W}}$ 85-124K, 96\% hydrolyzed) and 98\% sulfuric acid were purchased from Sigma Aldrich. Pure anhydrous ammonia gas was purchased from Airgas. Fibers were produced utilizing the lab scale Cyclone ${ }^{\mathrm{TM}}$ L-1000M from FibeRio Technology Corporation.

\subsection{Sample Preparation}

The nonwoven nitrogen doped carbon fiber mat was prepared as follows: A 10\% (wt./wt.) solution of PVA was prepared by adding and dissolving $1.11 \mathrm{~g}$ of PVA to $10 \mathrm{~mL}$ of deionized water and stirred for 4-6 hours in an oil bath at $75{ }^{\circ} \mathrm{C}$. The nonwoven mat was prepared as follows: $1 \mathrm{~mL}$ of the obtained 
PVA aqueous solution was injected into the Cyclone spinneret and spun at 7000 RPM for 1 minute. The fibers were allowed to collect on a substrate attached to a vacuum deposition system to form a nonwoven mat. This procedure was repeated until the mat was approximately 35 grams per square meter. The mat was treated with $98 \%$ sulfuric acid vapors in a heated semi-closed apparatus. Approximately 1-5 mL of sulfuric acid was placed in a beaker, and the nonwoven mat was sandwiched between the brim of the beaker and a glass funnel (or plate). The nonwoven sulfuric acid treated PVA fiber mat was washed in water until the acid residue was completely removed and then dried in air. Preoxidation was carried out at up to $200{ }^{\circ} \mathrm{C}$ in air. The nonwoven mat was then placed in a tube furnace and carbonized in nitrogen or pure ammonia gas, with a ramping rate between $2-10{ }^{\circ} \mathrm{C} \mathrm{min}^{-1}$, and held at the final temperature for less than 30 minutes.

\subsection{Characterization}

The morphology of the fiber mats was extensively studied by scanning electron microscopy (SEM, Sigma VP, Carl Zeiss, Germany). Elemental quantification of the developed fiber mats was studied with energy-dispersive X-ray spectroscopy (EDAX) (Model Octane Super within the SEM). The extent of doping of the carbon fibers with nitrogen was determined by X-ray photoelectron spectroscopy (XPS) with a Thermoscientific K- $\alpha$ XPS surface analysis instrument with a micro-focused monochromated $\mathrm{Al}$ $\mathrm{K}-\alpha$ X-ray source.

\section{$3 \quad$ Results and Discussion}

\subsection{Nitrogen Doping of Carbon Fiber}

Two heat-treating schemes were explored to determine the extent of nitrogen doping on the acid vapor treated mats. For the first method or route (Fig. 1), partial carbonization of the PVA nonwoven mat was carried out through the acid vapor treatment followed by washing of the mats to reduce acid traces [25]. The mats were fully carbonized when heat treated under nitrogen at $850{ }^{\circ} \mathrm{C}$. The temperature was then decreased to $500{ }^{\circ} \mathrm{C}$, and the mat was exposed to pure ammonia gas for one hour and then cooled to room temperature.

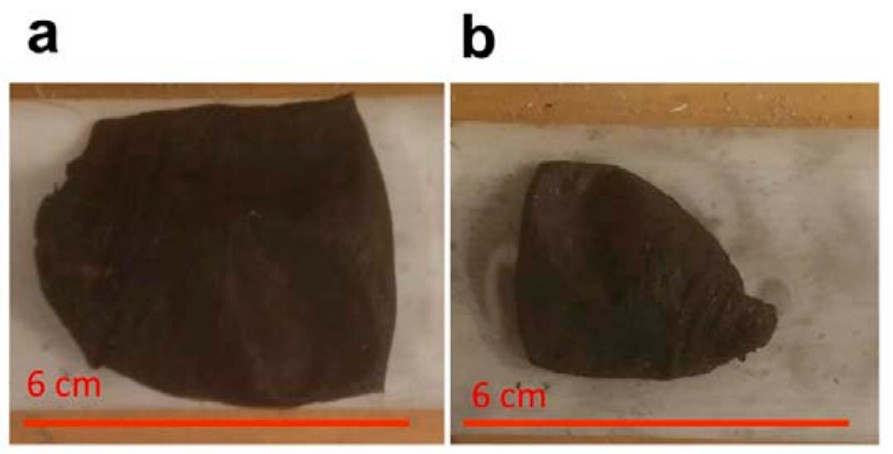

Figure 1. Nitrogen doped fibers - route 1: Carbonization procedure of the (a) sulfuric acid vapor treated polyvinyl alcohol nonwoven mat was carried out at $850^{\circ} \mathrm{C}$ followed by (b) ammonia treatment at $500{ }^{\circ} \mathrm{C}$.

In the second heating scheme, partial carbonization of the PVA nonwoven mat was also carried out with the acid vapor treatment followed by washing of the mats to reduce acid traces. However, the pyrolysis route involved heating the acid vapor treated mats under pure ammonia gas, from room temperature up to $850^{\circ} \mathrm{C}$, followed by cooling to room temperature. Results are shown in Fig. 2. 
a

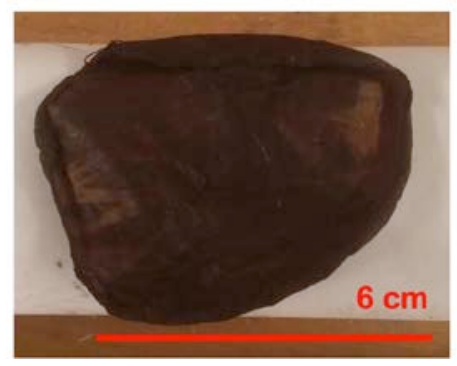

b



Figure 2. Nitrogen doped fibers route - 2: The PVA mat was first acid vapor treated (a) and then heat treated (b) in pure ammonia gas up to $850{ }^{\circ} \mathrm{C}$ at a ramping rate of $4^{\circ} \mathrm{C} \mathrm{min}^{-1}$.
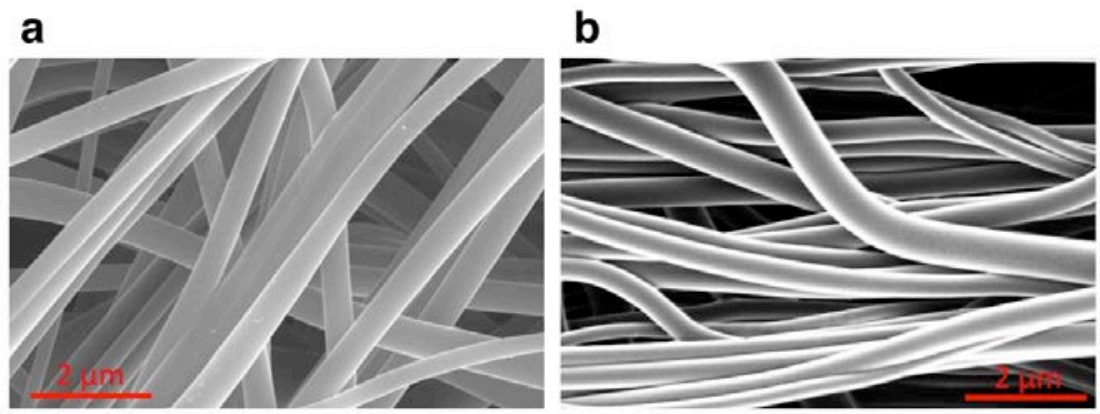

\section{C}

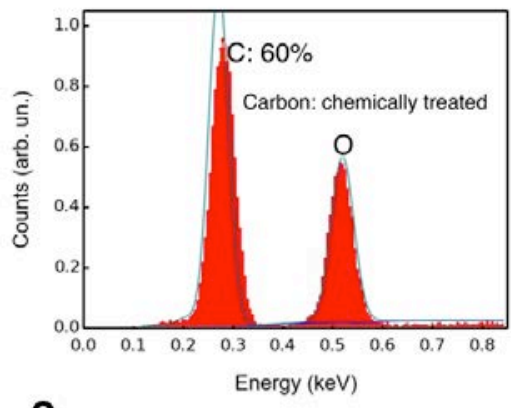

e
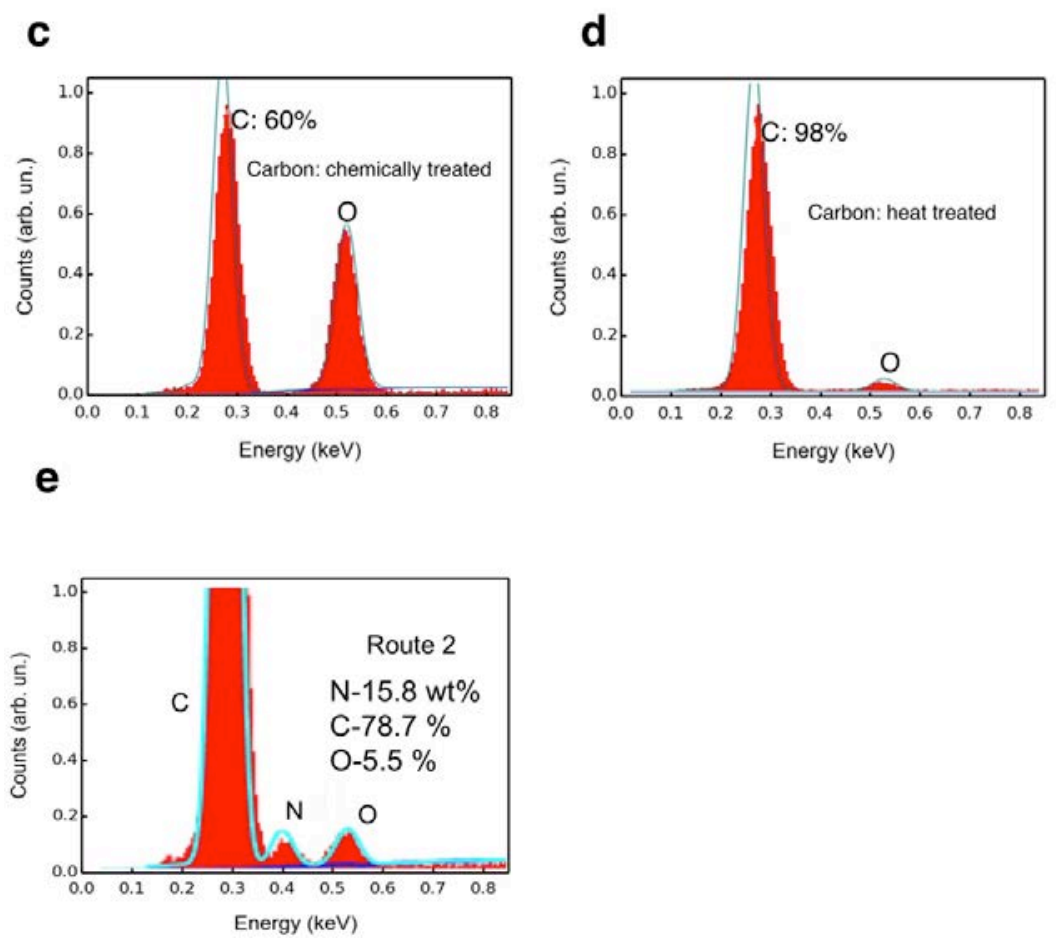

Figure. 3. SEM and EDAX spectroscopy of chemically and heat treated fibers for routes 1 and 2. Scanning electron microscope images are shown for the nitrogen doped fibers through route 1 (a) and 2 (b). EDAX spectra show evidence of carbon and oxygen atoms for (c) the sulfuric acid vapor treated PVA fibers. When the fibers were heat-treated the peak intensity of oxygen is reduced $(\mathrm{d})$. When the carbon fibers are heat treated under ammonia, via route 2 , the nitrogen content increases to $15.8 \mathrm{wt} . \%$ nitrogen. 


\subsection{Changes in Carbon Fiber Properties}

The chemical composition of the carbonized fibers for route 1 was analyzed using energy-dispersive Xray spectroscopy (EDAX). EDAX and SEM images of the fiber mats are also shown for route 2, during various stages of the carbon formation process (Fig. 3). There are basically two peaks representing carbon and oxygen (Fig. 3c), and the intensity of the oxygen peak is reduced significantly when the mat undergoes heat treatment in nitrogen (Fig. 3d).

Fig. 4. depicts an X-ray diffraction pattern of the nitrogen-doped carbon fibers following route 1. During acid treatment the crystalline structure of the fibers disappear and there is peak broadening and upshift to a higher angle centered between $2 \theta=20-30^{\circ}$. The acid and heat treated fibers show a broad (002) peak which corresponds to the disordered micrographitic stacking. Heat treatments up to $850{ }^{\circ} \mathrm{C}$ show a broad (10) peak between $2 \theta=40-50^{\circ}$ corresponding to the graphite plane [25, 26]. The crystal spectra indicate carbonization during acid vapor and subsequent heat treatment $\left(24^{\circ}\right)$, whereas the PVA precursor fibers have a crystalline peak at $2 \theta=19^{\circ}$. The ammonia treated carbon fibers, following route 1, show a broadening of the (002) graphite plane. Similar reports for carbon fiber studies have shown amorphous peaks centered around $20-30^{\circ}[28]$.



Figure. 4. X-Ray Diffraction patterns of PVA, acid treated PVA, carbon fiber, and nitrogen doped carbon fiber (route 1). The precursor PVA nanofibers exhibit a semi-crystalline structure with a narrow peak at $2 \theta=19^{\circ}$. During acid treatment the crystalline structure of the fibers disappears, and there is peak broadening and upshift to a higher angle centered between $2 \theta=20-30^{\circ}$. The acid and heat treated fibers show a broad (002) peak which corresponds to the disordered micrographitic stacking. Heat treatments up to $850^{\circ} \mathrm{C}$ show a broad (10) peak between $2 \theta=40-50^{\circ}$ corresponding to the graphite plane. The ammonia treated carbon fibers show a broadening of the (002) peak.

Fig. 5 and 6 show XPS spectra for the carbon fibers, produced by route 1 and 2, that were treated with ammonia. The survey spectrum (Fig. 5(a) and 6(a)), indicates the presence of carbon, nitrogen, and oxygen on both samples which is consistent with the EDAX spectra. For the sample produce by route 1 (Fig. 5(a)), the $\mathrm{C}$ 1s, $\mathrm{N}$ 1s and $\mathrm{O}$ 1s peaks appear at binding energies of 284.5, 399.6 and 532.8 $\mathrm{eV}$, with a weight percent concentration of 93.3 wt.\% C, 5.1 wt.\% O, and 1.6 wt.\% N, respectively. Fig. $5 \mathrm{~b}$, shows the $\mathrm{C} 1 \mathrm{~s}$ graphitization peak at $1225.1 \mathrm{eV}$, along with an inset schematic showing nitrogen incorporation, which is in agreement with the XRD data that indicate formation of the (002) graphitic plane between $20-27^{\circ}$. Several reports have indicated that nitrogen states between $400.5-401.5 \mathrm{eV}$ can be associated as quaternary or graphite-like nitrogen, which is incorporated into the structure of the extended aromatic $\pi$-system in carbon nanofiber [29-34]. The assignment of chemical groups from XPS spectra can be achieved through peak deconvolution obtained through curve fitting. The decomposed spectra for the $\mathrm{N}$ 1s state show a graphitic-like nitrogen peak centered at $400.6 \mathrm{eV}$ (Fig. 5(b, d)) which corresponds to a $\mathrm{N}$ atom bonded to three $\mathrm{sp}^{2}$ carbons.

Fig. 5(c) shows the deconvoluted spectra for seven $\mathrm{C}$ 1s bonding states with the corresponding binding energies: $\mathrm{C}_{\mathrm{I}}-284.5, \mathrm{C}_{\mathrm{II}}-285.7, \mathrm{C}_{\mathrm{III}}-286.5, \mathrm{C}_{\mathrm{IV}}-287.4, \mathrm{C}_{\mathrm{V}}-288.5, \mathrm{C}_{\mathrm{VI}}-289.8$, and $\mathrm{C}_{\mathrm{VII}}-291.2 \mathrm{eV}$. The main C-C bonding peak centered at $284.5 \mathrm{eV}\left(\mathrm{C}_{\mathrm{I}}\right)$ has the greatest intensity, and corresponds to $\mathrm{sp}^{2}$ 
bonding found in graphitic structures, while the peak at $285.7 \mathrm{eV}\left(\mathrm{C}_{\mathrm{II}}\right)$ can be assigned to the $\mathrm{C}-\mathrm{C} \mathrm{sp}^{3}$ bonding state. Previous reports by Ismagilov et al. have indicated that nitrogen doping of carbon fiber results in the $\mathrm{C}$ 1s peak shifting to higher binding energies from $284.3 \mathrm{eV}$ (undoped highly oriented pyrolytic carbon fiber) to $284.6 \mathrm{eV}$ (8.2 wt.\% for nitrogen doped) [29]. The shift is due to the disordering of the graphite-like structure after incorporation of nitrogen. Undoped carbon fiber produced herein has a $\mathrm{C}_{\mathrm{I}}$ peak at $284.6 \mathrm{eV}$, which is greater than the reported $\mathrm{C}$ 1s peak for highly oriented pyrolytic carbon fiber. With respect to the latter, graphite in carbon nanofiber is less ordered and has been reported to have a $\mathrm{C} 1 \mathrm{~s}$ graphitic peak at $284.5 \mathrm{eV}$, and may not show a $\mathrm{C}$ 1s peak shift when treated in an ammonia mixture [35]. The remaining five $\mathrm{C} 1 \mathrm{~s}$ bonding states can be assigned to the bonding of carbon to oxygen on the surface in the form of various functional groups [36-38]. The peak found at $286.5 \mathrm{eV}$ $\left(\mathrm{C}_{\mathrm{III}}\right)$ can be assigned to $\mathrm{C}-\mathrm{O}-\mathrm{R}(\mathrm{R}=\mathrm{C}, \mathrm{H})$, which can either be an epoxy $(\mathrm{C}-\mathrm{O})$, ether $(\mathrm{C}-\mathrm{O}-\mathrm{C})$, or hydroxyl $(\mathrm{C}-\mathrm{OH})$ group. The peak found at $287.4 \mathrm{eV}\left(\mathrm{C}_{\mathrm{IV}}\right)$ corresponds to the carbonyl $(-\mathrm{C}=\mathrm{O})$ found on the aldehyde/ketone groups. A carboxyl/carboxylate group $\left(\mathrm{O}=\mathrm{C}-\mathrm{OH} / \mathrm{O}=\mathrm{C}-\mathrm{O}^{-}\right)$can be assigned to the peak at $288.5 \mathrm{eV}\left(\mathrm{C}_{\mathrm{V}}\right)$ and $289.8 \mathrm{eV}\left(\mathrm{C}_{\mathrm{VI}}\right)$. The peak with the highest binding energy for the $\mathrm{C} 1 \mathrm{~s}$ state at $291.2 \mathrm{eV}\left(\mathrm{C}_{\mathrm{VII}}\right)$ can be assigned to the $\pi-\pi^{*}$ "shake-up" satellite, which accompanies the photoionization process of the 1 s electron in the conjugated $\pi$-system found in graphite [29].
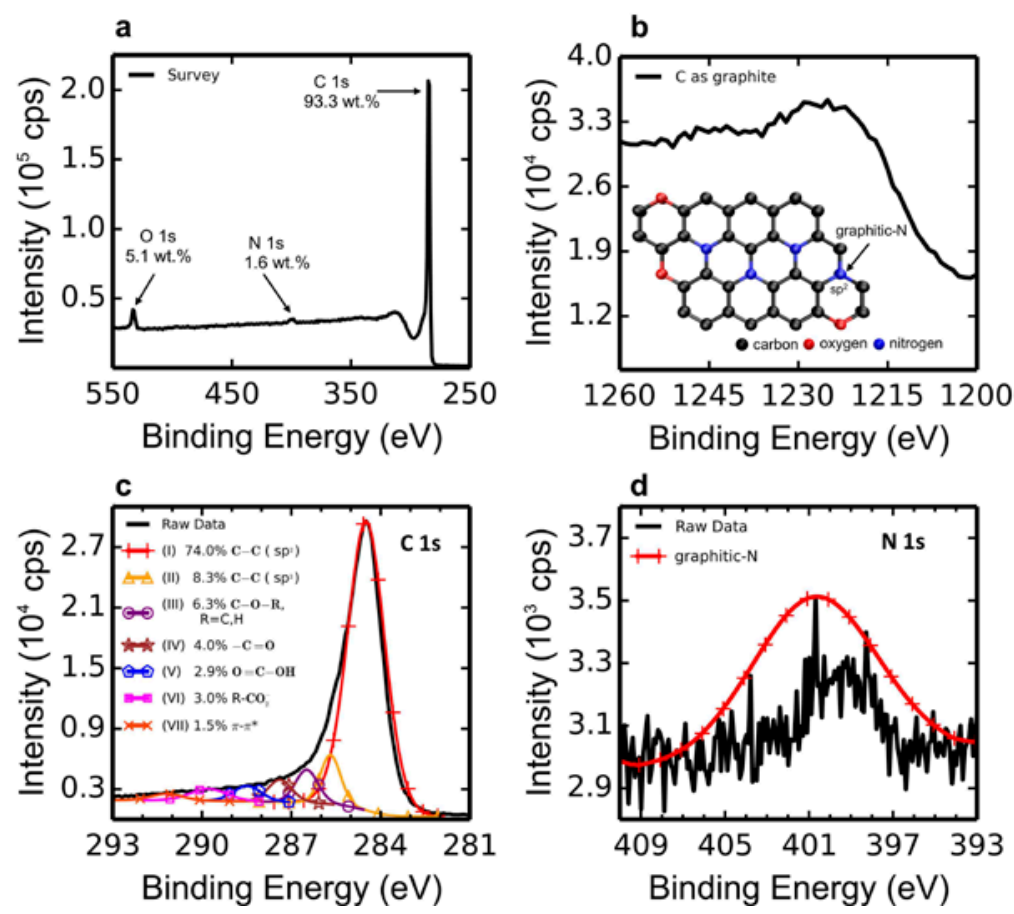

Figure 5. XPS of nitrogen doped carbon fiber - route 1. (a) The survey indicates the presence of carbon, oxygen, and nitrogen with a peak at $400.6 \mathrm{eV}$. (b) The peak at $1225.1 \mathrm{eV}$ indicates the presence of graphite (inset) and the decomposed C 1s states shown in (c) indicates a principal peak at $284.5 \mathrm{eV}$ corresponding to the $\mathrm{sp}^{2}$ hybridized $\mathrm{C}$ found in graphite. The deconvoluted N 1s state shows a bonding state at $400.6 \mathrm{eV}$, which can be assigned to a quaternary or graphitic type $\mathrm{N}$ found in graphite.

The XPS spectra of the sample produced by route 2 (Fig. 6a) show the $\mathrm{C} 1 \mathrm{~s}, \mathrm{~N}$ 1s and $\mathrm{O}$ 1s peaks at binding energies of $286.1,398.1$ and $532.1 \mathrm{eV}$, with a weight percent concentration of 78 wt.\% C, 14.3 wt.\% O, and 8.0 wt.\% N, respectively. Fig. 6(c) shows the deconvoluted spectra lines for the C 1s state where five bonding states were identified with the corresponding binding energies of $284.6\left(\mathrm{C}_{\mathrm{I}}\right), 286.3$ $\left(\mathrm{C}_{\mathrm{II}}\right), 287.8\left(\mathrm{C}_{\mathrm{III}}\right), 290.2\left(\mathrm{C}_{\mathrm{IV}}\right)$, and $291.7\left(\mathrm{C}_{\mathrm{V}}\right) \mathrm{eV}$. 

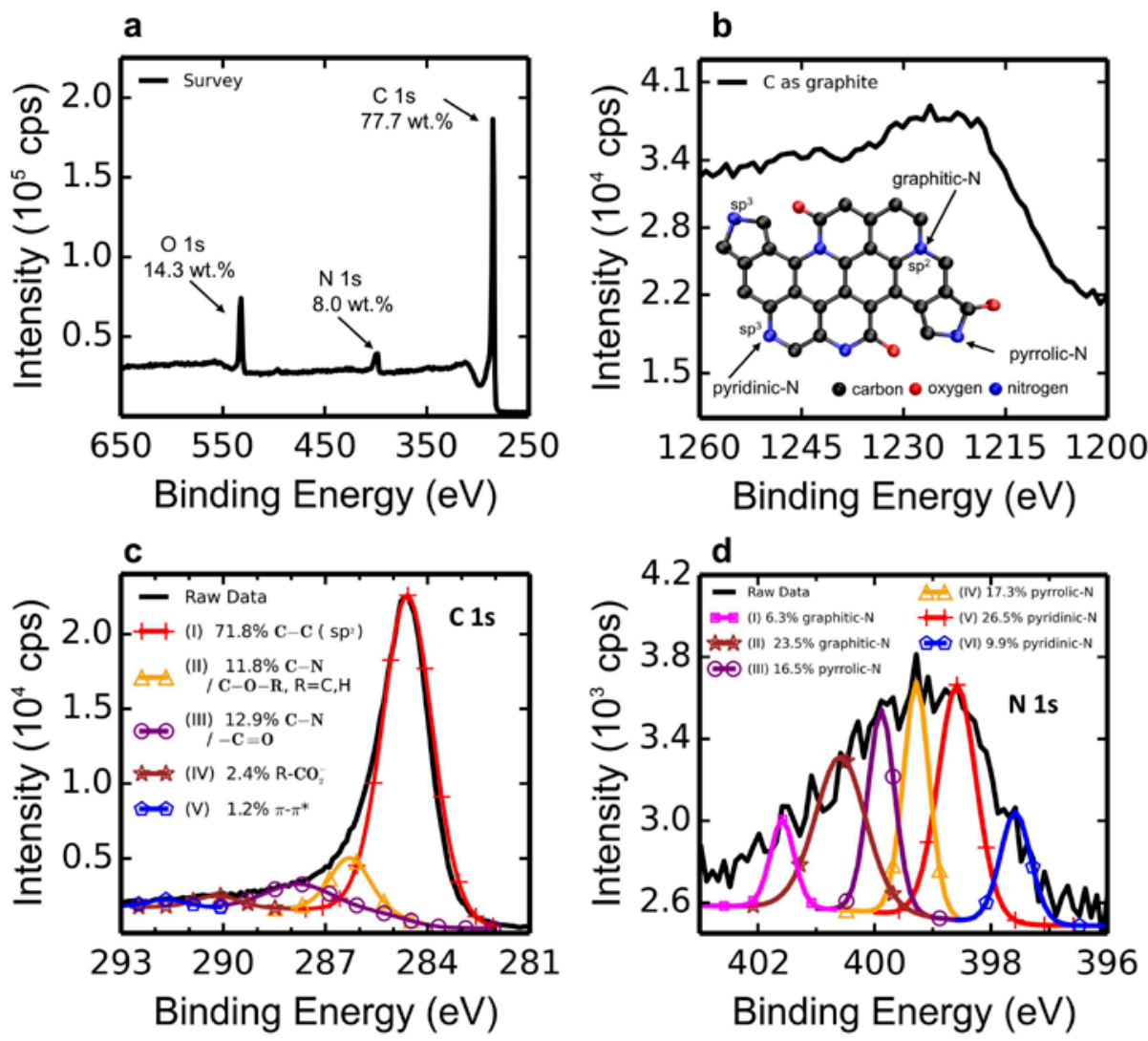

Figure 6. XPS of nitrogen doped carbon fiber - route 2. (a) The survey also indicates the presence of carbon, oxygen, and a nitrogen peak at $398.1 \mathrm{eV}$. b) The peak at $1226.1 \mathrm{eV}$ indicates the presence of graphite. The inset shows a schematic of nitrogen incorporated into the graphite structure. (c) A detailed analysis of the $\mathrm{C} 1 \mathrm{~s}$ peak indicates five 1s bonding states: a principal $\mathrm{sp}^{2}$ hybridized $\mathrm{C}-\mathrm{C}$ bond along with other carbon/nitrogen type functional groups. (d) The deconvoluted spectrum for The $\mathrm{N}$ 1s peak shows that the carbon framework has nitrogen incorporated within the graphitic ring structures (graphitic: $\mathrm{N}_{\mathrm{I}}-401.6 \mathrm{eV}, \mathrm{N}_{\mathrm{II}}-400.6$,) in addition to other $\mathrm{sp}^{3}$ hybridized nitrogen bonding states.

The principal $\mathrm{C}$ 1s binding energy peak $\left(284.6 \mathrm{eV}, \mathrm{C}_{\mathrm{I}}\right)$, for the $8 \mathrm{wt} . \% \mathrm{~N}$ doped carbon fiber produced by route 2 , is slightly greater than reported values for undoped carbon fiber $(284.3 \mathrm{eV})$. In one study, Ismagilov et al. showed that the C 1s peak shifted to higher binding energies from 284.3 to $284.6 \mathrm{eV}$ for an 8.2 wt.\% nitrogen doped carbon fiber, which was due to the increased structural disorder in the graphitic network [29]. For route 2, there are notable differences for the remaining $\mathrm{C}$ 1s bonding states, which can also be assigned to different bonding functionalities of carbon-oxygen on the surface [36-38]. Unlike route 1 , the $\mathrm{C}-\mathrm{C} \mathrm{sp}{ }^{3}$ hybridized bonding state is not evident. The $\mathrm{C}_{\mathrm{II}}$ bonding state $(286.3 \mathrm{eV})$ can be assigned to a $\mathrm{C}-\mathrm{O}-\mathrm{R}(\mathrm{R}=\mathrm{C}, \mathrm{H})$ and $\mathrm{C}-\mathrm{N}$ bond which can span from 285.2-288.5 eV [38]. This is evident from the increased bonding character, which is $11.8 \%$ for the $\mathrm{C}_{\mathrm{II}}$ state in route 2 compared to $6.3 \%$ for the same bonding functionality in route 1 . The $\mathrm{C}_{\mathrm{III}}$ state $(287.8 \mathrm{eV})$ may correspond to a carbonyl ( $-\mathrm{C}=\mathrm{O}$, found on the aldehyde/ketone groups) and a $\mathrm{C}-\mathrm{N}$ bond, given that the bonding state is $12.9 \%$, which is greater than the state corresponding to the carbonyl in route 1 at $4.0 \%$. The $\mathrm{C}_{\text {IV }}$ $(290.2 \mathrm{eV})$ bonding state can be assigned to a carboxylate $\left(\mathrm{O}=\mathrm{C}-\mathrm{O}^{-}\right)$, and the $\mathrm{C}_{\mathrm{V}}$ peak $(291.7 \mathrm{eV})$ with the highest binding energy to the $\pi-\pi *$ "shake-up" satellite [29, 39].

Fig. 6b, shows the $\mathrm{C} 1 \mathrm{~s}$ graphitization peak at $1226.1 \mathrm{eV}$ with an inset schematic representing the different bonding configurations of nitrogen in the graphitic plane. There are generally at least five different nitrogen bonding types that have been reported which fall into a range of different binding energies [29-34]: pyridinic-N (397.3-398.8 eV, 402.1-402.5 eV), pyrrolic-N (399.5-400.3 eV), pyridone-N $(400.2 \mathrm{eV})$, quaternary or graphitic-N (400.5-401.2 eV), and pyridinic oxide-N (403.5-405 eV). One 
report on the nitrogen doping of carbon fiber [31], containing carbon nanoparticles, showed a pyridinic state ranging from 396-400.5 eV, a pyrrolic state from 399-402 eV, and a graphitic state from 399-403.5 $\mathrm{eV}$. Deconvolution of the $\mathrm{N}$ 1s peak suggests that the carbon network is doped with three nitrogen types (Fig. 6d). Six N 1s bonding states were identified and denoted, with the corresponding binding energies, as: graphitic $\mathrm{N}_{\mathrm{I}}-401.6$, quaternary or graphitic ( $\mathrm{sp}^{2}$ hybridized) $\mathrm{N}_{\mathrm{II}}-400.6$, pyrrolic $\mathrm{N}_{\mathrm{III}}-399.9$, pyrrolic $\left(\mathrm{sp}^{3}\right.$ hybridized) $\mathrm{N}_{\mathrm{IV}}-399.3$, pyridinic $\mathrm{N}_{\mathrm{V}}-398.6$, and pyridinic $\mathrm{N}_{\mathrm{VI}}-397.6 \mathrm{eV}$, respectively [27-29]. Each of the three nitrogen bonding types (pyridinic, pyrrolic, and graphitic) shown in Fig. 6d has two peaks, which can be attributed to the bonding environment. For instance, the presence of oxygen on the surface of the graphitic network (14.3 wt.\% oxygen) suggests (inset Fig. 6b) two possible types of pyrrolic or pyridinic nitrogen: an N-C-C and N-C-O type bond. Graphitic-N can be found either in-plane or along the edge. Kiuchi et al. reported on the nitrogen doping of pyrolytic graphite prepared by low energy nitrogen ion sputtering and subsequent annealing at less than $800{ }^{\circ} \mathrm{C}[40]$. As the nitrogen concentration decreased, two graphitic nitrogen components were identified: a graphitic- $\mathrm{N}$ in the basal plane (nitrogen bonded to three carbon atoms) at $400.9 \mathrm{eV}$, and a graphitic- $\mathrm{N}$ in the zigzag edge and/or vacancy sites with a binding energies of $401.9 \mathrm{eV}$. The difference in the binding energy or chemical shifts is due to the chemical environment, e.g. placement of nitrogen atom at different sites or inequivalent positions. In general, the assignment of peaks and nitrogen coordination is not always straightforward [41], especially with overlapping peaks that appear within a narrow window or within the full-width-half-maximum (FWHM less than $2.5 \mathrm{eV}$ ). For this reason, theoretical models have often been used to assist in peak identification. Casanovas et al. carried out first principles calculations which suggested that the zigzag graphitic-N peak shifts to higher binding energy by approximately $1 \mathrm{eV}$ compared to the in-plane graphitic- $\mathrm{N}$ [42]. The graphitic-N peaks $\left(\mathrm{N}_{\mathrm{I}}-401.6\right.$ and $\left.\mathrm{N}_{\mathrm{II}}-400.6\right)$ reported herein follow a similar peak shift.

When the mats are nitrogen doped following route 1 , the surface nitrogen content increases to approximately $1.6 \mathrm{wt} . \%$ (Fig. 5a). The electrical conductivity was on average $6.1 \times 10^{-3} \mathrm{~S} \cdot \mathrm{cm}^{-1}$ (volume resistivity of $165 \Omega \cdot \mathrm{cm})$ for the acid vapor treated mats, which increased to $2.46 \mathrm{~S} \cdot \mathrm{cm}^{-1}(0.407 \Omega \cdot \mathrm{cm})$ for the carbon mats, and increased further to $4.6 \mathrm{~S} \cdot \mathrm{cm}^{-1}(0.22 \Omega \cdot \mathrm{cm})$ for the $1.6 \mathrm{wt} . \%$ nitrogen doped carbon fibers. The nitrogen content for the doped carbon fibers produced from route 2 ( 8 wt.\%), however, shows a much lower conductivity of $4.2 \times 10^{-2} \mathrm{~S} \cdot \mathrm{cm}^{-1}$ (volume resistivity of $24 \Omega \cdot \mathrm{cm}$ ). Ismagilov et al. reported on the doping of carbon nanofibers with varying concentrations of nitrogen (0$8.2 \mathrm{wt. \% )}$ produced by the decomposition of ethylene and an ethylene/ammonia mixture over a catalyst at $550{ }^{\circ} \mathrm{C}[29,35]$. In the latter study, the conductivity was $9.1 \mathrm{~S} \cdot \mathrm{cm}^{-1}$ for the undoped carbon fiber structure ('herringbone'), and $15.4 \mathrm{~S} \cdot \mathrm{cm}^{-1}$ for a $3.1 \mathrm{wt} . \%$ nitrogen doped carbon nanofiber. However, the conductivity decreased to $6.1 \mathrm{~S} \cdot \mathrm{cm}^{-1}$ for an $8.2 \mathrm{wt} . \%$ nitrogen doped carbon fiber sample. The decreased conductivity was due to the increased defectiveness of the graphite-like structure as shown by Raman spectroscopy (shown by the broadening of the $\mathrm{D}$ band and an increase in the ratio of integral intensities of lines D and G). A similar trend by Chiang et al., that involved the boron doping of carbon nanotubes, also demonstrated a reduction in conductivity with increased boron content which was due to the formation of defects [43].

Decreased conductivity, due to increased graphitic defects, in the nitrogen-doped carbon fiber is connected to the particular nitrogen bonding type (e.g. $\mathrm{sp}^{3}$ hybridized pyridinic-N). As mentioned, Ismagilov et al. showed that 1.7 and 3.1 wt.\% nitrogen doped carbon fiber preferentially contains a graphitic-N peak $(400.5 \mathrm{eV})$, which has an additional electron that can delocalize to the $\pi$-system in carbon fiber. However, at higher nitrogen concentrations of $8.2 \mathrm{wt} . \%$, the fraction of the pyridinic state increases $(398.7 \mathrm{eV})$; the pyridinic XPS peak intensity becomes greater than the graphitic-N and a broad peak (409 eV) corresponding to the pyridinic $\pi-\sigma^{*}$ transition appears (excitation of unshared electron pair to vacant $\sigma^{*}$ orbital). With respect to the latter, the increased pyridinic state therefore leads to an increase fraction of localized states or a decreased localization radius of the electron wave function (denoted as " $\mathrm{a}_{\mathrm{loc}}$ " where $\mathrm{a}_{\mathrm{loc}}=6.1 \mathrm{~nm}$ for $1.7 \mathrm{wt} . \% \mathrm{~N}$ and $\mathbf{a}_{\mathrm{loc}}=4.9 \mathrm{~nm}$ for $8.2 \mathrm{wt} . \% \mathrm{~N}$ ). This results in decreased current carrier mobility or conductivity in the sample.

With respect to the route 2 syntheses herein, the observed decrease in the electrical conductivity is due to the presence of additional $\mathrm{sp}^{3}$ hybridized nitrogen states (pyridinic and pyrrolic-N) which contribute to increased localized states. This is in contrast to route 1 where only one graphitic-N state (additional electron added to $\pi$-system) was incorporated into the carbon backbone at a lower nitrogen content of 1.6 wt.\%, which was shown to be more conductive. For route 2, there is a competition of two 
independent processes when incorporating nitrogen into the graphite lattice. As a result, an optimum nitrogen doping concentration may exist, whereby adding an additional electron carrier to the delocalized $\pi$-system (graphitic-N) on the graphite layer, can overcome the disordering of the graphite lattice (from pyridinic or pyrrolic states).

\section{Conclusion}

In this study we showed the production of nitrogen doped carbon fiber nonwoven mats from a low-cost water soluble polymer precursor using the high-throughput Forcespinning ${ }^{\circledR}$ (FS) technology. The developed doped carbon fibers have potential use as n-type carbon materials where improvement in thermoelectric high power output is needed. The nitrogen doping method allows for the introduction of electron rich impurities into the carbon framework, thereby creating donor states, and lead to improved conductivity with respect to the un-doped carbon fibers. For industrialization of carbon-based materials, this would be an ideal production method since it is simple and effective for low-cost production, scalability, and reproducibility. In terms of processability and performance, the carbon-based material can be functionalized or modified by doping to create advance or novel materials for thermoelectric applications. The presented carbon production method is a novel and efficient way to produce carbon fiber, and the dehydration induced process, coupled with low temperature carbonization, presents an attractive method to develop other types of doped carbon nonwoven mats (e.g. p-type carbon materials). The developed carbon based materials could be used "as is" or embedded in polymer composites for reinforcement. Further investigations are underway to study the thermoelectric properties of modules containing $\mathrm{p}$ and n-type nonwoven multifunctional carbon fiber mats.

Acknowledgments. The authors gratefully acknowledge support received from National Science Foundation under PREM grant No. DMR1523577.

\section{References}

1. W. H. Choi, M. J. Choi, and J. H. Bang. "Nitrogen-Doped Carbon Nanocoil Array Integrated on Carbon Nanofiber Paper for Supercapacitor Electrodes," ACS Applied Materials \& Interfaces, vol. 7, no. 34, pp. 1937019381, 2015. http://dx.doi.org/10.1021/acsami.5b05527

2. Y. Du, K. Cai, S. Chen, H. Wang, S. Z. Shen, R. Donelson, and T. Lin. "Thermoelectric Fabrics: Toward Power Generating Clothing," Scientific Reports, vol. 5, no. 6411, pp. 1-6, 2015. http://dx.doi.org/10.1038/srep06411

3. C. A. Hewitt, D. S. Montgomery, R. L. Barbalace, R. D. Carlson, and D. L. Carroll. "Improved thermoelectric power output from multilayered polyethylenimine doped carbon nanotube based organic composites," Journal of Applied Physics, vol. 115, no. 18, pp. 1845021-1845025, 2014. http://dx.doi.org/10.1063/1.4874375

4. O. Bubnova, Z. U. Khan, A. Malti, S. Braun, M. Fahlman, M. Berggren, and X. Crispin. "Optimization of the thermoelectric figure of merit in the conducting polymer poly(3,4-ethylenedioxythiophene)," Nature Materials, vol. 10, no. 6, pp. 429-433, 2011. http://dx.doi.org/10.1038/nmat3012

5. S. Han and D. D. L. Chung. "Through-thickness thermoelectric power of a carbon fiber/epoxy composite and decoupled contributions from a lamina and an interlaminar interface," Carbon, vol. 52, pp. 30-39, 2013. http://dx.doi.org/10.1016/j.carbon.2012.08.071

6. H. J. Goldsmid, "Recent Trends in Thermoelectric Materials Research I - Chapter 1 Introduction," in Semiconductors and Semimetals, vol. 69. Elsevier, 2001, pp. 1-24.

7. S. K. Bux, R. G. Blair, P. K. Gogna, H. Lee, G. Chen, M. S. Dresselhaus, R. B. Kaner, et al. "Nanostructured Bulk Silicon as an Effective Thermoelectric Material," Advanced Functional Materials, vol. 19, no. 15, pp. 24452452, 2009. http://dx.doi.org/10.1002/adfm.200900250

8. X. Tan, H. Liu, Y. Wen, H. Lv, L. Pan, J. Shi, and X. Tang. "Optimizing the thermoelectric performance of zigzag and chiral carbon nanotubes," Nanoscale Research Letters, vol. 7, no. 1, pp. 1-7, 2012. http://dx.doi.org/10.1186/1556-276X-7-116 
9. R. Czerw, M. Terrones, J. C. Charlier, X. Blase, B. Foley, R. Kamalakaran, N. Grobert, et al. "Identification of Electron Donor States in N-Doped Carbon Nanotubes," Nano Letters, vol. 1, no. 9, pp. 457-460, 2001. http://dx.doi.org/10.1021/nl015549q

10. K. Bradley, S.-H. Jhi, P. G. Collins, J. Hone, M. L. Cohen, S. G. Louie, and A. Zettl. "Is the Intrinsic Thermoelectric Power of Carbon Nanotubes Positive?," Physical Review Letters, vol. 85, no. 20, pp. 4361-4364, 2000. http://dx.doi.org/10.1103/PhysRevLett.85.4361

11. G. S. Park, J.-S. Lee, S. T. Kim, S. Park, and J. Cho. "Porous nitrogen doped carbon fiber with churros morphology derived from electrospun bicomponent polymer as highly efficient electrocatalyst for Zn-air batteries," Journal of Power Sources, vol. 243, pp. 267-273, 2013. http://dx.doi.org/10.1016/j.jpowsour.2013.06.025

12. Y. M. Choi, D. S. Lee, R. Czerw, P. W. Chiu, N. Grobert, M. Terrones, M. Reyes-Reyes, et al. "Nonlinear Behavior in the Thermopower of Doped Carbon Nanotubes Due to Strong, Localized States," Nano Letters, vol. 3, no. 6, pp. 839-842, 2003. http://dx.doi.org/10.1021/nl034161n

13. D. A. Baker and T. G. Rials. "Recent advances in low-cost carbon fiber manufacture from lignin," Journal of Applied Polymer Science, vol. 130, no. 2, pp. 713-728, 2013. http://dx.doi.org/10.1002/app.39273

14. J. Spender, A. L. Demers, X. Xie, A. E. Cline, M. A. Earle, L. D. Ellis, and D. J. Neivandt. "Method for production of polymer and carbon nanofibers from water-soluble polymers.," Nano letters, vol. 12, pp. 3857-3860, 2012. http://dx.doi.org/10.1021/nl301983d

15. M. Inagaki, Y. Yang, and F. Kang. "Carbon nanofibers prepared via electrospinning," Advanced Materials, vol. 24, no. 19, pp. 2547-2566, 2012. http://dx.doi.org/10.1002/adma.201104940

16. L. Feng, S. Li, H. Li, J. Zhai, Y. Song, L. Jiang, and D. Zhu. "Super-hydrophobic surface of aligned polyacrylonitrile nanofibers," Angewandte Chemie International Edition, vol. 41, no. 7, pp. 1221-1223, 2002. http://dx.doi.org/10.1002/1521-3773(20020402)41:7\%3C1221::AID-ANIE1221\%3E3.0.CO;2-G

17. C. J. Ellison, A. Phatak, D. W. Giles, C. W. Macosko, and F. S. Bates. "Melt blown nanofibers: Fiber diameter distributions and onset of fiber breakup," Polymer, vol. 48, no. 11, pp. 3306-3316, 2007. http://dx.doi.org/10.1016/j.polymer.2007.04.005

18. T. Nakajima, K. Kajiwara, and J. E. McIntyre, Advanced Fiber Spinning Technology. WoodHead Publishing Limited, Abington Hall, 2009.

19. S. Ramakrishna, K. Fujihara, W.-E. Teo, T.-C. Lim, and Z. Ma, An Introduction to Electrospinning and Nanofibers. World Scientific Publishing Co. Pte. Ltd., 2005.

20. A. Greiner and J. H. Wendorff. "Electrospinning: a fascinating method for the preparation of ultrathin fibers," Angewandte Chemie International Edition, vol. 46, no. 30, pp. 5670-5703, 2007. http://dx.doi.org/10.1002/anie.200604646

21. K. Sarkar, C. Gomez, S. Zambrano, M. Ramirez, E. D. Hoyos, H. Vasquez, and K. Lozano. "Electrospinning to Forcespinning $^{\mathrm{TM}}$," Materialstoday, vol. 13, pp. 12-14, 2010. http://dx.doi.org/10.1016/S1369-7021(10)70199-1

22. M. A. Hunt, T. Saito, R. H. Brown, A. S. Kumbhar, and A. K. Naskar. "Patterned functional carbon fibers from polyethylene.," Advanced Materials, vol. 24, no. $\quad 18, \quad$ pp. $2386-2389, \quad 2012$. http://dx.doi.org/10.1002/adma.201104551

23. B. Weng, F. Xu, A. Salinas, and K. Lozano. "Mass production of carbon nanotube reinforced poly(methyl methacrylate) nonwoven nanofiber mats," Carbon, vol. $75, \quad$ pp. 217-226, 2014. http://dx.doi.org/10.1016/j.carbon.2014.03.056

24. Y. Rane, A. Altecor, and K. Lozano. "Preparation of superhydrophobic Teflon® AF 1600 sub-micron fibers and yarns using the Forcespinning ${ }^{\mathrm{TM}}$ technique," Journal of Engineered Fibers and Fabrics, vol. 8, no. 4, pp. 88-95, 2013. http://www.jeffjournal.org/papers/Volume8/V8I4\%2811\%29 K. Lozano.pdf

25. L. D. Cremar, J. Acosta-Martinez, A. Villarreal, A. Salinas, L. Wei, Y. Mao, and K. Lozano. "Multifunctional carbon nanofiber systems mass produced from water soluble polymers," Chemical Fibers International vol. 66, no. 1, pp. 40-42, 2016.

26. L. D. Cremar, J. Acosta-Martinez, A. Villarreal, A. Salinas, L. Wei, Y. Mao, and K. Lozano. "Multifunctional carbon nanofiber systems mass produced from water soluble polymers and low temperature processes," TextileTechnology: Chemical Fibers International Fiber production. No. 1, Document 6, pp. 1-17, 2016. http://textination.de/de/document/1145985479292875/2.0/ 
27. L. D. Cremar, J. Acosta-Martinez, A. Villarreal, A. Salinas, and K. Lozano. "Mechanical and electrical characterization of carbon nanofibers produced from water soluble precursors," Materials Today Communications, vol. 7, pp. 134-139, 2016. http://dx.doi.org/10.1016/j.mtcomm.2016.04.006

28. U. K. Fatema, A. J. Uddin, K. Uemura, and Y. Gotoh. "Fabrication of carbon fibers from electrospun poly(vinyl alcohol) nanofibers," $\quad$ Textile Research Journal vol. 81, pp. 659-672, 2010. http://dx.doi.org/10.1177/0040517510385175

29. Z. R. Ismagilov, A. E. Shalagina, O. Y. Podyacheva, A. V. Ischenko, L. S. Kibis, A. I. Boronin, Y. A. Chesalov, et al. "Structure and electrical conductivity of nitrogen-doped carbon nanofibers," Carbon, vol. 47, no. 8, pp. 1922-1929, 2009. http://dx.doi.org/10.1016/j.carbon.2009.02.034

30. T. Sharifi, M. Valvo, E. Gracia-Espino, R. Sandström, K. Edström, and T. Wågberg. "Hierarchical selfassembled structures based on nitrogen-doped carbon nanotubes as advanced negative electrodes for Li-ion batteries and 3D microbatteries," Journal of Power Sources, vol. 279, pp. 581-592, 2015. http://dx.doi.org/10.1016/j.jpowsour.2015.01.036

31. G. Panomsuwan, N. Saito, and T. Ishizaki. "Nitrogen-Doped Carbon Nanoparticle-Carbon Nanofiber Composite as an Efficient Metal-Free Cathode Catalyst for Oxygen Reduction Reaction," ACS Applied Materials 8 Interfaces, vol. 8, no. 11, pp. 6962-6971, 2016. http://dx.doi.org/10.1021/acsami.5b10493

32. F. Lai, Y.-E. Miao, Y. Huang, Y. Zhang, and T. Liu. "Nitrogen-Doped Carbon Nanofiber/Molybdenum Disulfide Nanocomposites Derived from Bacterial Cellulose for High-Efficiency Electrocatalytic Hydrogen Evolution Reaction," ACS Applied Materials \& Interfaces, vol. 8, no. 6, pp. 3558-3566, 2016. http://dx.doi.org/10.1021/acsami.5b06274

33. A. Hachimi, B. Merzougui, A. Hakeem, T. Laoui, G. M. Swain, Q. Chang, M. Shao, et al. "Synthesis of Nitrogen-Doped Carbon Nanotubes Using Injection-Vertical Chemical Vapor Deposition: Effects of Synthesis Parameters on the Nitrogen Content," Journal of Nanomaterials, vol. 2015, no. 453725, pp. 1-9, 2015. http://dx.doi.org/10.1155/2015/453725

34. L-C. Chen, P-Y. Peng, L-F. Lin, T. C. K. Yang, and C.-M. Huang. "Facile Preparation of Nitrogen-Doped Activated Carbon for Carbon Dioxide Adsorption," Aerosol and Air Quality Research, vol. 14, no. 3, pp. 916-927, 2014. http://dx.doi.org/10.4209/aaqr.2013.03.0089

35. A. E. Shalagina, Z. R. Ismagilov, O. Y. Podyacheva, R. I. Kvon, and V. A. Ushakov. "Synthesis of nitrogencontaining carbon nanofibers by catalytic decomposition of ethylene/ammonia mixture," Carbon, vol. 45, no. 9, pp. 1808-1820, 2007. http://dx.doi.org/10.1016/j.carbon.2007.04.032

36. W. H. Lee, J. G. Lee, and P. J. Reucroft. "XPS study of carbon fiber surfaces treated by thermal oxidation in a gas mixture of $\mathrm{O}_{2} /\left(\mathrm{O}_{2}+\mathrm{N}_{2}\right)$," Applied Surface Science, vol. 171, no. 1-2, pp. 136-142, 2001. http://dx.doi.org/10.1016/S0169-4332(00)00558-4

37. A. Bratt and A. R. Barron. "XPS of Carbon Nanomaterials," Available: http://cnx.org/content/m34549/1.2/

38. J. F. Moulder, W. F. Stickle, P. E. Sobol, and K. D. Bomben, Handbook of X-Ray Photoelectron Spectroscopy. Perkin-Elmer Corporation, 1992.

39. E. Andreoli and A. R. Barron. "Correlating Carbon Dioxide Capture and Chemical Changes in Pyrolyzed Polyethylenimine-C60," Energy \& $\quad$ Fuels, vol. 29, no. 7, pp. 4479-4487, 2015. http://dx.doi.org/10.1021/acs.energyfuels.5b00778

40. H. Kiuchi, T. Kondo, M. Sakurai, D. Guo, J. Nakamura, H. Niwa, J. Miyawaki, et al. "Characterization of nitrogen species incorporated into graphite using low energy nitrogen ion sputtering," Physical Chemistry Chemical Physics, vol. 18, no. 1, pp. 458-465, 2016. http://dx.doi.org/10.1039/c5cp02305j

41. K. Artyushkova, B. Kiefer, B. Halevi, A. Knop-Gericke, R. Schlogl, and P. Atanassov. "Density functional theory calculations of XPS binding energy shift for nitrogen-containing graphene-like structures," Chemical Communications, vol. 49, no. 25, pp. 2539-2541, 2013. http://dx.doi.org/10.1039/c3cc40324f

42. J. Casanovas, J. M. Ricart, J. Rubio, F. Illas, and J. M. Jiménez-Mateos "Origin of the Large N 1s Binding Energy in X-ray Photoelectron Spectra of Calcined Carbonaceous Materials," Journal of the American Chemical Society, vol. 118, no. 34, pp. 8071-8076, 1996. http://dx.doi.org/10.1021/ja960338m

43. W.-H. Chiang, G.-L. Chen, C.-Y. Hsieh, and S.-C. Lo. "Controllable boron doping of carbon nanotubes with tunable dopant functionalities: an effective strategy toward carbon materials with enhanced electrical properties," RSC Advances, vol. 5, no. 118, pp. 97579-97588, 2015. http://dx.doi.org/10.1039/c5ra20664b 